\title{
Physical Activity and Sociodemographic Variables Related to Global Health, Quality of Life, and Psychological Factors in Breast Cancer Survivors
}

\author{
Efrossini D. Patsou', George T. Alexias', Fotios G. Anagnostopoulos', Michalis V. Karamouzis²* \\ 'Department of Psychology, Panteion University of Social and Political Sciences, Athens, Greece \\ ${ }^{2}$ Medical School, National and Kapodistrian University of Athens, Athens, Greece
}

\section{Article Info}

\section{Article Notes}

Received: November 16, 2018

Accepted: January 29, 2019

\section{${ }^{*}$ Correspondence:}

Dr. Michalis V. Karamouzis, MD, PhD, Associate Professor, Department of Biological Chemistry, Medical School, University of Athens, 75, M. Asias Street, 11527 Athens, Greece; Telephone No: +30 2107210960 , Fax No: +30 2107210960 , E-mail: m_karam@otenet.gr \& mkaramouz@med.uoa.gr.

(c) 2019 Karamouzis MV. This article is distributed under the terms of the Creative Commons Attribution 4.0 International License

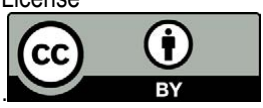

\section{ABSTRACT}

Breast cancer is the most common cancer affecting women worldwide. Women have many disturbing feelings and psychological side effects during diagnosis, treatment and survivorship which include depression, anxiety, low self-esteem and poor quality of life. The aim of the study was to examine the associations between physical activity, global health, quality of life, depressive symptoms, self-esteem, and anxiety in breast cancer survivors after finishing cancer treatment and through survivorship. Demographic variables such as marital status, education, and income, as well as cancer stage and level of physical activity were tested as predictors of depressive mood, anxiety, selfesteem and quality of life in 171 Greek breast cancer survivors.

We are presenting a commentary on the paper in order to highlight the most important conclusions of the study and suggest areas for further investigation.

\section{Introduction}

Breast cancer is by far the most common cancer among women worldwide $^{1}$. Early detection and improvements in treatment have increased the survival rates of breast cancer patients ${ }^{2-3}$. Unfortunately, there are psychological side effects (depression, anxiety) during treatment ${ }^{4}$ while in some women depression remains or appears throughout survivorship ${ }^{5-6}$. Low quality of life is also recorded in breast cancer survivors and may lead in poor adherence to treatment ${ }^{7-9}$. On the other hand, there is some evidence that long term survivors seem to have levels of functioning and quality of life that are comparable to those of the general female population ${ }^{10}$.

Many researchers have shown that physical activity is very effective for the decrease of the psychological side effects and the improvement of quality of life $\mathrm{e}^{4}$. A recent meta-analysis showed that moderate aerobic exercise interventions with an optimal duration of $\geq 135$ minutes for up to 12 weeks resulted in significant differences in depressive symptoms between exercise intervention groups and control groups when it comes in patients under treatment. In the same study exercise interventions in patients post- treatment yielded also a significant effect on depressive mood ${ }^{11}$. In another study which included 2525 patients with stage I-III breast cancer undergoing adjuvant therapy, those who had 75 minutes of vigorous or 150 minutes of moderate exercise per week had significantly better quality of life at 6 and 12 months after treatment than those who were inactive ${ }^{12}$. 
Findings for anxiety and low self-esteem during survivorship are not given priority in studies worldwide. World Health Organization (WHO) recommends physical exercise for decreased levels of depression and anxiety in breast cancer survivors ${ }^{1}$. So far, not so many studies have examined associations between depressive symptoms, anxiety, self-esteem and quality of life, as well as differences between active and less active breast cancer survivors in the long period after having finished treatment of any kind and through survivorship. Despite the limitations and methodological weaknesses of relevant studies which include mostly white participants, small sample sizes, and non reported differences in socioeconomic status, it is known that physical activity is an effective way for managing depression symptoms throughout or after survivorship. Additionally, there is a lack of knowledge about the relationship between physical activity, income, marital status, education, stage of cancer, and depressive mood, anxiety, self-esteem, global health and quality of life, quite some time after treatment and through survivorship in younger and older survivors. It has been shown that cancer has a significant impact on the lives of younger survivors because they need to manage the psychological and emotional distress that come with both cancer diagnosis and treatment. They have a lot of stress because they don't expect to be ill, especially suffering from cancer and they may have many family burdens and social responsibilities ${ }^{13}$.

Our results showed significant associations between physical activity and depressive symptoms, anxiety, selfesteem, global health and quality of life, when we compare active to inactive or less active women in a long-term period after having finished treatment and through survivorship. Physical activity was positively associated with self-esteem, global health and quality of life, and negatively associated with depressive symptoms and anxiety even long after having finished treatment and through survivorship. It was showed also that physical activity was a significant predictor of less depressive symptoms and anxiety, higher self-esteem, better global health and quality of life in younger as well as in older survivors long after having finished treatment and through survivorship.

It was concluded that physical activity was the most important variable related to psychological outcomes and quality of life for survivors below 51 years old. Income, educational level and stage of cancer were also related to quality of life and self-esteem, while marital status was not related to quality of life for younger survivors. These findings are novel. Other studies have also found that depression and anxiety were significantly worse in younger survivors ${ }^{14-16}$ without providing specific information about patient characteristic or other variables such as physical activity.
For survivors above 52 years old, physical activity was also significantly related to depressive symptoms, anxiety, self-esteem and quality of life, while income, education and cancer stage were significantly related to self-esteem and quality of life. Marital status seemed to be related to depressive symptoms and cognitive function involved in quality of life. Other studies for older survivors have shown that marital status and education were predictors of better quality of life and anxiety in older survivors ${ }^{17-18}$. For selfesteem, there is not much evidence and this finding is novel.

The results of the study showed that physical activity was significantly related to a better psychological mood states, with less depressive symptoms and anxiety, higher self-esteem and better quality of life in younger and older survivors too, many months after having finished treatment and through survivorship. Moreover, there were novel findings about other factors such as income, education, marital status and stage of cancer and their relation with the psychological factors and the quality of life among younger and older breast cancer survivors.

Almost all the studies have measured levels of physical activity through self-reported questionnaires or salivary flow rates and not by an objective way of measurement. One of the strengths of the current study is the use of an objective measurement for the physical activity level, Vo2max test in the treadmill, in addition to the self-reported questionnaire. This combination strengthens the results of the study and reduces bias.

Given the difficulty of finding a sample with the characteristics we wanted (at least one and a half year finished any cancer treatment for stage I-IV cancer and absence of other diseases) we consider that one hundred and seventy one patients who finally participated in the study were enough for increased power of the study. Participants were recruited from public and private hospitals which was another strength of the study. One limitation was that participants were only from Attica and more specifically from the capital city of Athens, which means that survivors from non-urban areas were not included, which might be a study limitation because sociodemographic factors might be different. Something that should have been taken into account and it did not, was chronic pain, especially in younger survivors and survivors with a metastatic disease and their quality of life. According to recent studies, younger age, metastasis and chemotherapy and radiation after surgery are associated with chronic pain which lead to higher anxiety and depression and low quality of life ${ }^{19-21}$. Despite the fact that most of these studies used either retrospective or crosssectional research methods which is a limitation, chronic pain could have been a mediator for depression and anxiety. From that point of view it would have been good to examine the associations between physical activity and 
chronic pain in younger and older survivors as well as with the stage of cancer, something that was not done in this research. Finally, another issue which would be important to be considered is work transition as it has been shown that breast cancer survivors often experienced changes in work status during their survivorship time. Lower educational level is positively associated with job loss and lower quality of life $\mathrm{e}^{22}$.

Our results indicated that physical activity and exercise are associated with psychological mood states in breast cancer survivors after finishing any kind of treatment, as well as that physical activity and the patient characteristics may influence psychological functioning in younger and older survivors after finishing treatment and through survivorship. This is very important in order to implement interventions to reduce unpleasant and disturbing feelings and improve quality of life in younger as well in older survivors. Moreover, we could have employed further analysis on physical functioning and on the differences in symptoms between active and inactive group of patients. This would have given us further information about health related quality of life in breast cancer survivors.

\section{Author contribution}

\section{Concept/Design: E. Patsou}

Drafting \& Revising critically the article: G. Alexias, F. Anagnostopoulos \& M. Karamouzis

Final approval of the version to be submitted: M.V

Karamouzis

\section{References}

1. World Health Organization - Cancer Country Profiles, 2014.

2. Doyle N. Cancer survivorship: evolutionary concept analysis. J Adv Nurs. 2008; 62: (4), 499-509.

3. Zainal NR, Nik-Jaafar NR, Baharudin A, et al. Prevalence of Depression in Breast Cancer Survivors: a Systematic Review of Observational Studies. Asian Pac J Cancer Prev. 2013; 14: 2649-2656.

4. Brown JC, Huedo-Medina TB, Pescatello LC, et al. The Efficacy of Exercise in Reducing Depressive Symptoms among Cancer Survivors: A Meta-Analysis. PLoS ONE. 2012; 7: 30955.

5. Massie MJ. Prevalence of Depression in Patients With Cancer. J Natl Cancer Inst. 2004; 32: 57-71.

6. Burgess C, Cornelius V, Love $\mathrm{S}$, et al. Depression and anxiety in women with early breast cancer: five year observational cohort study. BMJ. 2005; 330: 702.

7. Ganz PA, Desmond KA, Leedham B, et al. Quality of life in long-term, disease-free survivors of breast cancer: a follow-up study. J Natl Cancer Inst. 2002; 94: 39-49.

8. Perna FM, Craft L, Freud KM, et al. The effect of a cognitive behavioral exercise intervention on clinical depression in a multiethnic sample of women with breast cancer: A randomized low fitnessled trial. Int J Sport Exerc Psychol. 2010; 8: 36-47.

9. Van Oers HM. Exercise effects on mood in breast cancer patients. SA J Sports Med. 2012; 25: 55-59.

10. Craft LL, Vaniterson EH, Helenowski IB, et al. Exercise effects on depressive symptoms in cancer survivors: a systematic review and meta-analysis. Cancer Epidemiol Biomarkers Prev. 2012; 21: 3-19.

11. Patsou ED, Alexias GD1, Anagnostopoulos FG, et al. Effects of physical activity on depressive symptoms during breast cancer survivorship: a meta-analysis of randomised control trials. ESMO open. $2017 ; 2$ (5): $\mathrm{e} 000271$.

12. Di Meglio A, El-Mouhebb M, Michiels S, et al. 1684PD_PR Physical activity (PA) and patterns of quality of life (QOL) after adjuvant chemotherapy (CT) for breast cancer (BC). Annals of Oncology. 2018; 29(suppl_8): mdy424-086.

13. Butow P, Price MA, Shaw JM, et al. Clinical pathway for the screening, assessment and management of anxiety and depression in adult cancer patients: Australian guidelines. Psycho-Oncology. 2015; 24(9): 987-1001.

14. Courneya KS, McKenzie DC, Mackey JR, et al. Effects of Exercise Dose and Type During Breast Cancer Chemotherapy: Multicenter Randomized Trial. JNCI, 2013; 105: 1821-1833.

15. Courneya KS, Friedenreich CM. Relationship between exercise during treatment and current quality of life among survivors of breast cancer. J Psychosoc Oncol. 1998; 15(3-4): 35-57.

16. Speck RM, Courneya KS, Mâsse LC, et al. An update of low fitness physical activity trials in cancer survivors: a systematic review and meta-analysis. J Cancer Surviv. 2010; 4(2): 87-100.

17. Knobf MT, Thompson AS, Fennie K, et al. The Effect of a CommunityBased Exercise Intervention on Symptoms and Quality of Life. Cancer Nurs. 2014; 37: 43-50.

18. Burgess C, Cornelius V, Love $\mathrm{S}$, et al.. Depression and anxiety in women with early breast cancer: five year observational cohort study. Bmj. 2005; 330: 702.

19. Poleshuck EL, Katz J, Andrus CH, et al. Risk factors for chronic pain following breast cancer surgery: a prospective study. The Journal of Pain. 2006; 7(9): 626-634.

20. Macdonald L, Bruce J, Scott NW, et al. Long-term follow-up of breast cancer survivors with post-mastectomy pain syndrome. British journal of cancer. 2005; 92(2): 225.

21. Hamood R, Hamood H, Merhasin I, et al. Chronic pain and other symptoms among breast cancer survivors: prevalence, predictors, and effects on quality of life. Breast cancer research and treatment. 2018; 167(1): 157-169.

22. Hamood R, Hamood H, Merhasin I, et al. Work Transitions in Breast Cancer Survivors and Effects on Quality of Life. Journal of Occupational Rehabilitation. 2018; 1-14. 